\title{
Characterizing Political Talk on Twitter: A Comparison Between Public Agenda, Media Agendas, and the Twitter Agenda with Regard to Topics and Dynamics
}

\author{
Oliver Posegga \\ University of Bamberg \\ oliver.posegga@uni-bamberg.de
}

\author{
Andreas Jungherr \\ University of Konstanz \\ andreas.jungherr@gmail.com
}

\begin{abstract}
Social media platforms, especially Twitter, have become a ubiquitous element in political campaigns. Although politicians, journalists, and the public increasingly take to the service, we know little about the determinants and dynamics of political talk on Twitter. We examine Twitter's issue agenda based on popular hashtags used in messages referring to politics. We compare this Twitter agenda with the public agenda measured by a representative survey and the agendas of newspapers and television news programs captured by content analysis. We show that the Twitter agenda had little, if any, relationship with the public agenda. Political talk on Twitter was somewhat stronger connected with mass media coverage, albeit following channel-specific patterns most likely determined by the attention, interests, and motivations of Twitter users.
\end{abstract}

\section{Introduction}

Social media platforms like Twitter, Reddit, and Facebook have become an important part of modern society and serve as spaces to share information and engage in conversations that touch on nearly every aspect of daily life. The growing acceptance, use, and relevance of these technologies have inspired research into a wide range of social phenomena by scholars from a variety of disciplines [1]. One of the more prominent research lines investigates how individuals use such technologies to consume, spread, and discuss news and opinions in political contexts [2]. Understanding political talk online has become an important line of research, which also has received much public attention outside of scientific communities. Not least in the very public discussion on the role of social media in political campaigns, such as their perceived role in the emergence and distribution of misinformation.

One of the more frequently analyzed platforms is the microblogging service Twitter, which has become a prominent space for political talk. Since the 2008 US-Presidential election, political campaigns all over the world have found strong echoes in Twitter messages commenting on candidates, parties, campaigns, and politics in general [3]. This has made Twitter a new space in which public political talk in the form of tweets promises insights into the topics politically vocal Twitter users pay attention to, interact with, and comment on. Twitter, as a text-based onlineservice, permits researchers to measure these objects of political attention and thereby develop a ranked list of topics which at any given time were the focus of politically vocal Twitter-users - a Twitter agenda.

However, interpreting and understanding this agenda is challenging. While the computational nature of Twitter makes it trivially easy to determine a Twitter agenda, the data provided by Twitter falls primarily into the category of digital trace data, i.e., observed traces of digital social interaction emerging from an online information system. While this type of data enables scholars to observe social interaction on an unprecedented scale [4], it usually carries little information on the context of its creation. Thus, the opportunities provided by digital trace data come with a variety of challenges, two of which lie at the core of this study: First, interpreting digital trace data without additional information on the context of its creation is difficult and can be subject to strong limitations [5]. Second, it is often unclear how insights derived from digital trace data relate to established theories, especially when those have been developed based on earlier, sparser datasets [1].

In response to the first issue, scholars have called for careful consideration of the assumptions involved in working with digital trace data to avoid validity issues $[5,6]$. Further, mixed methods designs have been suggested to overcome the issues arising in this 
context [7, 8]; Triangulating quantitative analyses of digital trace data with qualitative assessments of additional data sources (e.g. interviews, observations, or archival data) has enabled scholars to gain insights into the causal mechanisms underlying observable patterns of social interaction online $[9,10]$. In the context of analyzing political talk online, scholars have, for example, combined digital trace data with survey data in order to measure exposure effects [11, 12] and data documenting topical coverage in other media to determine mutual influence patterns [13-15].

With regards to the second issue, Watts [16] points out that while many studies, using large-scale datasets documenting social interactions online, introduced a vast number of innovative labels for seemingly new and astonishing phenomena, at a closer look they contained little novelty. Making a connection between the phenomena emerging from platforms like Twitter and established theories requires a rigorous reexamination of their underlying assumptions in the light of the characteristics and affordances of such platforms [1, 5]. We build on these insights in comparing political agendas emerging from survey responses, journalistic coverage in newspapers and television, and from political talk on Twitter.

Traditionally, communication research has seen an agenda as an ordered list of "topics the media and public are paying attention to and regard as important," [17, xiii]. In the beginning, agenda-setting research focused on the analysis of public and media agendas. This focus has been gradually expanded to also include agendas of politicians, legislators, interest groups, and others. A further extension to include prominent topics emerging from political talk on Twitter looks like a logical next step [e.g., 13, 18]. Still, the very nature of Twitter raises issues that researchers have to address in their interpretation of Twitter-based agendas. Especially two characteristics of Twitter make it likely for a list of prominent political topics identified on Twitter to diverge from lists based on answers given in surveys or political media coverage. These are Twitter's data generating process as a microblogging service-affording users to post pithy expressions of their thoughts, reactions, or concerns of the current moment-and its skewed user base - unrepresentative of the general population. In this article, we test this assumption by systematically comparing the political Twitter agenda to the public agenda, the newspaper agenda, and the television agenda during the months leading up to the 2013 federal election in Germany.

Based on data collected during the campaign for Germany's federal election in 2013, we compare the agenda emerging from political talk on Twitter with the public agenda measured by surveys [19], the newspaper agenda, and the television agenda measured by content analyses of major newspapers [20], and television news programs [21]. This comparison will focus on ranked lists of prominent topics as well as temporal dynamics. The analysis will show when the Twitter agenda diverges from and converges with the public and the media agendas. The analysis does stop short of systematically analyzing causal links between different agendas. While these causal links lie at the center of agenda-setting research [17], any such analysis requires first a better understanding of the characteristics of the Twitter agenda which we aim to provide here.

\section{Background}

Agenda setting is one of the pillars of political communication research [17]. The approach relies on identifying ranked lists of issues in political media coverage and on the public's mind. This is achieved by content analysis of political coverage in newspapers and on television and by population surveys. Two of the basic and often replicated findings of agendasetting research are that both lists - the media and the public agenda - correlate strongly and that the media agenda at a given time influences the public agenda at a later time [17]. Issue salience thus appears to flow from the media to the public agenda. While early agenda-setting research took the media agenda more or less as a given, increasingly researchers also focused on factors influencing the emergence of the media agenda. With this also came an extension of attention to other possible agendas (such as the policy agenda) and interactions between different agendas.

With the growing adoption of the internet, agendasetting research has increasingly focused on digital services and their interaction with public and media agendas. Prior studies demonstrated that media coverage of political issues led to an increase in issuerelated activity on electronic bulletin boards [e.g., 22]. Issues emphasized on political candidates' websites, and blogs were shown to influence issue salience in the media [e.g., 23]. A special focus of agenda-setting research has been the influence of blogs on traditional media. The causal relationship and strength of the transference of issue salience between traditional media and political blogs are contested. On the one hand, Lee [24] and Heim [25] found a strong correlation between traditional media coverage and blog agendas. On the other hand, Meraz [26] showed that blogs did not uniformly follow issue cues given by traditional media. Issue agendas of left-leaning bloggers in the U.S. corresponded with issue agendas of traditional media, while those of right-leaning 
bloggers correlated strongly amongst themselves but only weakly with the media agenda. Additionally, Wallsten [27] showed that the transfer of issue salience between mainstream media and political blogs during the US-presidential campaign of 2004 was bidirectional.

This body of research emphasizes the strong interconnection between traditional and new media, illustrating that it is not possible to identify one dominating - in other words agenda-setting - partner but instead showing a relationship of shifting influence. Similar patterns were documented for agendas measured on other internet-based services, such as Google [e.g., 28] or YouTube [e.g., 29]. This research underscores the value of identifying political agendas on digital services but also emphasizes that one should expect channel-specific characteristics in the agendas determined in different communication environments.

The nature of Twitter and its use makes it highly likely that lists of political topics identified in tweets diverge from the public agenda. This is due to Twitter's data generating process and the composition of its user base. Twitter data are digital trace data; they document events of users' public interactions with the service and are found rather than purposefully collected [5]. They document tweets that users posted in reaction to a wide variety of stimuli and following a wide variety of motives [2]. Contrast this with the traditional approach to measuring the public agenda, which relies on a very specific stimulus of surveying respondents for their view of the most important political topic of the day. It is to be expected that answers to this well-specified survey stimulus capture different topics than lists based on communication observed on Twitter, which arises from a wide variety of stimuli [30]. The first measurement strategy probably provides a more or less deliberate reflection of what respondents deem important. In contrast, the second likely yields a flickering map of topics of interest to politically vocal Twitter users during specific time intervals.

Also, Twitter's politically vocal user-base appears to be heavily skewed, if compared to the general population. It tends to be younger, more strongly interested in politics, even to the point of being politicaly partisan, while also more likely to be participating politically beyond Twitter [e.g., 31]. So even if Twitter provided a mirror image of objects of political attention, the reflection would only encompass objects of attention and interest of a very specific population [32].

In light of this, it appears more plausible that the Twitter agenda would reflect the media agenda. Temporal patterns of political talk on Twitter have been shown to be highly reactive to political media coverage [e.g., 14, 33]. This is not surprising, given the collective focus of attention political media events, like televised debates, news events, or high-profile political talk shows, can garner. Still, it is not clear that this temporal connection in volume also translates into a connection to the issues talked about. On this question, the evidence appears to be mixed. While some studies find clear connections between issues talked about in news media and on Twitter [e.g., 18], some find only weak or no links [e.g., 34, 35], while still others find evidence of some connection but also of Twitter-specific patterns [13, 14]. As specifics deviate strongly between these studies, it is difficult to compare or identify the reasons for these deviant findings directly.

At the same time, it might be that political talk on Twitter focuses on topics distinct from public opinion or political media coverage. In other contexts, it has been shown that references to politics on Twitter did not offer a true reflection of political reality. Instead, references appear to result from a filtering process by Twitter users' decision to post a tweet referring to politics. The reflection of political reality emerging from Twitter messages is, therefore, skewed by the attention, interests, and motivations of Twitter users $[2,36]$. This has consequences for the emergence of prominent topics on Twitter. For example, topics at the center of political media coverage should emerge prominently on the Twitter agenda, as well as topics of public controversy, scandals, or media events. Topics less in the focus of current coverage or controversy should be less prominent, irrespective of their relative prominence on the public agenda.

Different still, it might be that Twitter's affordances drive the prominence of political topics in tweets. Various studies have illustrated activists' use of Twitter for coordinating and publicizing collective action and protests [e.g., 37, 38]. The prominence of Twitter for these groups and their supporters might be reflected in the political topics addressed in tweets, thereby leading to differences between the Twitter agenda and media agendas. Further, political elites, have used Twitter to promote topics of interest to them actively, consciously trying to influence or circumvent political coverage in traditional media [39], the most prominent example currently being Donald Trump [40]. If picked up by large numbers of supporters, topics introduced through these strategic uses might also lead political topics identified in Twitter messages to diverge from those identified in media coverage.

Thus, we are left with mixed expectations for the relationship between the Twitter agenda and the two traditional agenda types. Given this, we establish to which of the two discussed scenarios, convergence 
with or divergence from public and media agendas of the Twitter agenda, our findings correspond most. Accordingly, we focus on the following research question: Does the Twitter agenda correspond with public or media agendas?

\section{Methods}

We compare the Twitter agenda with public and media agendas during the campaign for the German Federal Election in 2013. We choose this specific case for two reasons. First, since its inception in 2006, Twitter rapidly gained popularity in Germany, and by 2013, seven percent of German online users were on Twitter [41]. While Twitter's user base remained largely stagnate since then [42], the platform maintains an important role as a communication channel for politically vocal users, candidates, parties, and the media [43]. Second, agenda-setting research in the context of Federal Elections in Germany is well established. The German Longitudinal Election Study (GLES) publicly provides a high-quality data set, documenting the public agenda as well as the agendas emerging from television and newspaper coverage [19-21]. This provides us with a promising foundation for our research design, which triangulates digital trace data collected from Twitter with data used in traditional agenda-setting research. Thus, the case serves as an ideal starting point to analyze political talk online, and more specifically, the Twitter agenda and its relationship to other agenda types.

Our methodological approach consists of three steps. First, we determine the strength of the correspondence between the Twitter, public, and media agendas by analyzing correlations between the respective lists of ranked topics. We compare snapshots of the agendas (ranked lists of prominent topics aggregated over the complete observation period) as well as the unaggregated time series of the daily agendas (ranked lists of prominent topics for each day of our observation period). Second, we provide an in-depth comparison of the ten most prominent topics on the different agendas and analyze patterns of divergence and correspondence between

\footnotetext{
${ }^{1}$ Frankfurter Rundschau (FR), Süddeutsche Zeitung (SZ), Frankfurter Allgemeine Zeitung (FAZ), Die Welt (Welt), Die Tageszeitung (TAZ), and the Bildzeitung (BILD)

2 ARD, ZDF, RTL, and Sat. 1

3 Parties: cdu, cducsu, csu, spd, die_linke, dielinke, linke, linkspartei, linken, buendnis 90 , bündnis90, bündnis90diegrünen, bündnis90grüne, bündnisgrüne, bündnisgrünen, die gruenen, die_grünen, diegrünen, gruene, grüne, grünen, gruenen, fdp, afd, piraten, piratenpartei. Candidates: merkel, angie_merkel, angelamerkel, angela_merkel, seehofer, horstseehofer,
}

them. Third, we extend this analysis by examining the time series of the mention volume of the ten most prominent topics on the Twitter agenda and establish whether topics on the Twitter agenda precede, correspond, or follow their counterparts in the public and media agendas. In summation, this procedure allows us to reveal the structure of the Twitter agenda and its dynamics on an aggregated level, on a temporal level for the most prominent topics, and its relationship with other agendas.

Before we can compare issue agendas across media, we have to identify salient topics in the public's mind, in mainstream media, and on Twitter. Traditionally, the public agenda is measured using surveys and some variation of the question "Please identify the most pressing political topic" [17]. For the following analysis, we used the GLES Rolling Cross Section (RCS). This CATI survey queried a random sample of 7,882 respondents from July 8 to September 21, 2013 [19]. Respondents were asked to identify the two most pressing political problems in Germany. We aggregated the weighted mentions of the most and the second most important topics and ranked them according to their shares of the total count of all topic mentions.

To identify the media agenda, we used two publicly available datasets provided by the GLES documenting political coverage in newspapers and on television between 23 June and 21 September 2013. The GLES Campaign Content Analysis newspaper dataset contains a hand-coded account of the content of six major German newspapers ${ }^{1}$ [20]. The GLES Campaign Content Analysis television dataset offers a hand-coded set of the content of the major news programs of Germany's four major TV stations ${ }^{2}$ [21].

To establish a Twitter agenda, we collected all messages posted by users referring to politics between July 1 and September 21, 2013. To identify these users, we identified politically relevant messages posted during the campaign through the social media data vendor Gnip. We queried Gnip's Historical Powertrack for messages containing the names of political parties, candidates, campaign-related phrases, and keywords related to campaign-related media events. ${ }^{3}$

horst_seehofer, steinbrück, steinbrueck, peer_steinbrück, peer_steinbrueck, gysi, gregorgysi, gregor_gysi, wagenknecht, sahrawagenknecht, sahra_wagenknecht, göring-eckardt, goeringeckardt, göringeckardt, goeringeckardt, katringöring-eckardt, katringöringeckardt, katringoering-eckardt, katringoeringeckardt, katrin_göring-eckardt, katrin_goering-eckardt,

katrin_göringeckardt, katrin_goeringeckardt, katrin_göringeckardt, katrin_goeringeckardt, katrin_göring_eckardt, katrin goering eckardt, katringoering eckardt, katringöring_eckardt, göring_eckardt, goering_eckardt, trittin, jürgentrittin, juergentrittin, jürgen_trittin, juergen_trittin, brüderle, 
This resulted in a dataset containing 6,677,795 messages posted by 1,248,667 users mentioning at least one of the words on our list. We filtered the dataset to only include messages of users who had opted for German as Twitter-interface language to focus on the German-speaking Twitter population. We consciously decided against using Twitter's automated language detection to remove messages posted in other languages than German. The field documents the results of an automated process, which remains a black box to researchers not affiliated with Twitter and thereby might negatively impact data quality. While potentially underestimating the total number of tweets referring to political actors, our approach produces a robust and reproducible data set of relevant messages. We evaluated the reliability of this choice by manually coding the language of 3,809 randomly selected users using two coders. After reaching a sufficient agreement (Cohen's kappa of 0.957 and a Krippendorff's alpha of 0.957), the coders identified 9.14\% German-speaking users, compared to $7.9 \%$ identified via the interface-language. Following this procedure resulted in the selection of $1,390,571$ messages posted by 98,149 users. We then collected all messages posted by these users by either querying their message archives through Twitter's API or, in case messages posted during the time span of the analysis were not available anymore, bought messages posted by these users through Gnip. This led us to a final data set of $39,062,065$ messages posted by 98,149 users between July 1 and September 21, 2013. In determining the ranked Twitter agenda, we decided to rely on hashtags. Hashtags are widely used on Twitter to establish a topical context for a message [2]. They offer a window into topics users consciously address in their messages. For this analysis, we focused on the 10,000 most often used hashtags in messages posted between July 1 and September 21, 2013 by 98,149 politically vocal Twitter users in Germany. This enables us to identify the most prominent political topics in messages by politically vocal users during the campaign.

To allow a direct comparison between the thus identified agendas, we adjusted each dataset to the one covering the shortest time span. This was the GLES RCS survey offering daily survey responses from July 8 to September 21. The analyses reported below, therefore, are restricted to this period.

In identifying political issues in survey responses, newspaper and television coverage, and Twitter hashtags, we followed the same coding scheme used by GLES. This provided us with a detailed

bruederle, rainerbrüderle, rainerbruederle, rainer_brüderle, rainer_bruederle, lucke, berndlucke, bernd_lucke. Campaign: categorization of political issues across the datasets allowing us the direct comparison between issue agendas. The coding scheme differentiates between topics corresponding with the general categories politics, polity, and policy. The category politics refers to topics focused on the "political process which evolves as succession of actions of political actors" [20], polity refers to topics corresponding with "the structural dimension, concerning the overall institutional order of the political system as well as its institutions" [20], and policy covers "the content dimension, i.e., measures and programs developed, decided upon and implemented by political actors" [20]. In this article, we focus on topics falling into the categories polity and policy. This allows us to focus on the correspondence between political issues corresponding with the structural dynamics of German politics and specific policies. Mentions of political actors or parties and their campaigns, covered by the category politics, are therefore excluded from our analysis. This left us with 275 topical categories. The coding scheme is organized hierarchically with increasing degrees of specificity. Coders were trained to follow an issue to its appropriate level of contextual correspondence. For example, a coder identifies a reference to the civil war in Syria. Thus, she identifies her item as referring to policy (code 3000), foreign affairs (code 3100), international conflicts or wars in general (code 3180), and finally the civil war in Syria (code 3184). If she had found a mention of a conflict not covered by a specific code, she would have chosen the category international conflicts or wars in general (code 3180). This parsimonious identification of topical references in survey responses, political coverage in newspapers, television, and Twitter hashtags allows us to identify the detailed correspondence between agendas without relying too strongly on general categories.

To identify the public, newspaper, and television agendas, we relied on the coding provided by the GLES in their publicly available datasets (for quality metrics of the original coding see [19-21]). To code the 10,000 most prominent hashtags in our Twitter dataset, we developed a codebook based on the original GLES codebooks to allow us to compare prominent topic across the data sets directly. We had three coders code the 10,000 most popular hashtags in our dataset. We had each of them code 4,000 hashtags. Of these, 1,000 were coded by each of our coders to identify the quality of their coding. Based on the shared codes, we calculated a Fleiss' kappa of 0.538, an average pairwise Cohen's kappa of 0.536 and a

btw13, bundestagswahl, wahlkampf, btw2013, wahl13. Events: tvduell, wahlarena, dreikampf, kanzlerduell. 
Krippendorff's alpha of 0.538 . Thus, providing us with an acceptable coding quality while reflecting the challenge of correctly identifying the thematic context of hashtags. Of the original 10,000 most prominent hashtags, our coders identified 1,659 as topically relevant in correspondence with our codebook. Between July 1 and September 21, 2013, these hashtags were mentioned $3,129,655$ times in 2,128,797 messages.

\section{Results}

\subsection{Congruence between the Twitter, Public, and Media Agendas}

In the first step of our analysis, we focus on the correlation between the Twitter, public, and media agendas. Across datasets, coders identified items in correspondence with 275 issues in the codebook. Not all of these were present in all datasets. The total set of issues we can compare between the three agenda types, therefore, varies between 100 and 160 . Table 1 shows the rank and share correlations between the agendas. The table clearly shows that the Twitter agenda is only very weakly correlated with the public agenda by both metrics. With regard to the correlation between the Twitter agenda and the newspaper and television agendas, we find somewhat higher rank correlations, while the share correlations between the agendas are clearly higher. However, we should not overestimate these values as the share correlations are largely driven by correspondingly low coverage shares of issues in the long tail of the coverage distribution.

Table 1. Share and Rank Correlations

\begin{tabular}{llll}
\hline Agendas & $\begin{array}{l}\text { Rank Correlation } \\
\text { (Spearman's Rho) }\end{array}$ & $\begin{array}{l}\text { Share Correlation } \\
\text { (Pearson's r) }\end{array}$ & $\mathrm{N}$ \\
\hline Twitter-Public & 0.12 & 0.08 & 160 \\
Twitter-Newspaper & $0.46^{* * *}$ & $0.86^{* * *}$ & 140 \\
Twitter-TV & $0.40^{* * *}$ & $0.84^{* * *}$ & 100 \\
Public-Newspaper & $0.31^{* * *}$ & $0.17^{*}$ & 150 \\
Public-TV & 0.08 & 0.11 & 110 \\
Newspaper-TV & $0.65^{* * *}$ & $0.92^{* * *}$ & 130 \\
\hline Note: ${ }^{* * *} \mathrm{p}<0.001,{ }^{* *} \mathrm{p}<0.01{ }^{*}{ }^{*} \mathrm{p}<0.05$ & &
\end{tabular}

It is conceivable that correlations between agendas might be higher on specific dates than on others. To examine potential fluctuations in the strength of correlations between the Twitter agenda and other agendas, in Figure 1, we plot the daily rank correlations over the course of the campaign. This shows no significant temporal variations in the strength of the correlations between the Twitter and the public agenda. Correlations between Twitter and media agendas are fluctuating more heavily.
As Figure 2 shows, these fluctuations are largely driven by the comparatively small count of observations available across the datasets. These results show that issues raised in Twitter messages corresponded very little with issues on the public agenda as measured by the most-important-issue question. We also see a somewhat stronger, but far from deterministic correlation between the Twitter agenda and the newspaper and television agendas. This points to the importance of channel-specific agenda dynamics on Twitter.

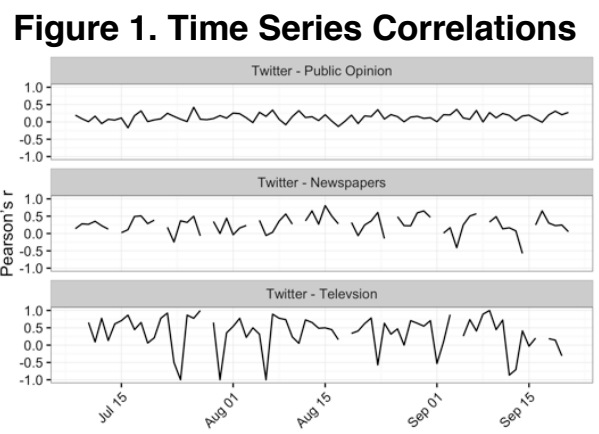

Note: Time series of agenda correlations between July 8 and September 21, 2013

Figure 2. Observations per Time Series

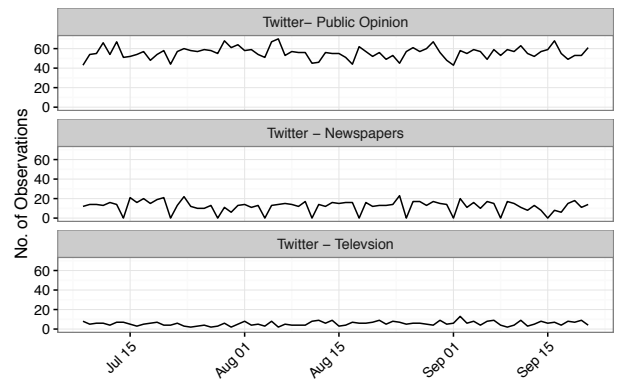

Note: Time series of the number of observations as a basis for correlations between July 8 and September 21

\subsection{Cross-Comparison of Prominent Issues}

In the second step of our analysis, we directly compare the ten most prominent topics on all four agendas. The results, presented in Table 2, show a clear divergence between the most prominent topics of each agenda. The public agenda is dominated by worries about unemployment, the Euro crisis, education, the minimum wage, and pensions. In contrast, the newspaper agenda is dominated by the coverage of the NSA-spying scandal, the Syrian civil war, child abuse, the financial crisis, and asylum policy. The television agenda is also dominated by coverage of the NSA scandal, the Syrian civil war, a controversy about drone requisitions, a controversy 
about tolls on motorways, and the Egyptian revolution. The Twitter agenda focuses on comments on the NSA scandal, government surveillance, the Egyptian revolution, the Syrian civil war, and controversy over the wrongful imprisonment of Gustl Molath. It is also important to note that the Twitter agenda appears to be much more focused on one topic than the other agendas. $25.6 \%$ of all issue mentions fall on hashtags referring to the NSA scandal. This level of concentration is much higher than that found in the other agendas, where top issues attracted somewhere between $12 \%$ and $15 \%$ of mentions. This supports the notion that Twitter offers a view of political reality mediated by the interests of politically vocal Twitter users $[2,36]$.

Table 2. Top 10 Agenda Issues

\begin{tabular}{|c|c|c|c|c|c|c|c|c|}
\hline \multirow{2}{*}{\multicolumn{2}{|c|}{$\begin{array}{l}\text { Public } \\
\text { Issue }\end{array}$}} & \multicolumn{3}{|c|}{ Newspaper } & \multirow{2}{*}{$\begin{array}{l}\text { TV } \\
\text { Issue }\end{array}$} & \multicolumn{3}{|c|}{ Twitter } \\
\hline & & $\%$ & Issue & $\%$ & & $\%$ & Issue & $\%$ \\
\hline$\overline{1}$ & Unemployment & 8.9 & NSA Scandal & 12.2 & $\begin{array}{l}\text { NSA } \\
\text { Scandal }\end{array}$ & 15.1 & NSA Scandal & 25.6 \\
\hline 2 & Euro & 8.6 & $\begin{array}{l}\text { Syrian Civil } \\
\text { War }\end{array}$ & 4.4 & $\begin{array}{l}\text { Syrian Civil } \\
\text { War }\end{array}$ & 8.4 & $\begin{array}{l}\text { Government } \\
\text { Surveillance }\end{array}$ & 4.9 \\
\hline 3 & $\begin{array}{l}\text { Education } \\
\text { Policy }\end{array}$ & 5.0 & Child Abuse & 3.0 & Drones & 3.5 & $\begin{array}{l}\text { Egyptian } \\
\text { Revolution }\end{array}$ & 4.9 \\
\hline 4 & Minimum Wage & 4.0 & $\begin{array}{l}\text { Financial } \\
\text { Crisis, } \\
\text { Greece }\end{array}$ & 2.8 & $\begin{array}{l}\text { Tolls on } \\
\text { Motorways }\end{array}$ & 3.1 & $\begin{array}{l}\text { Syrian Civil } \\
\text { War }\end{array}$ & 4.7 \\
\hline 5 & Pensions & 3.6 & $\begin{array}{l}\text { Asylum } \\
\text { Policy }\end{array}$ & 2.5 & $\begin{array}{l}\text { Egyptian } \\
\text { Revolution }\end{array}$ & 2.8 & Gustl Mollath & 3.5 \\
\hline 6 & $\begin{array}{l}\text { Distributive } \\
\text { Justice }\end{array}$ & 3.3 & Drones & 2.5 & $\begin{array}{l}\text { Floods, } \\
2013\end{array}$ & 2.6 & $\begin{array}{l}\text { Traffic Policy } \\
\text { and Public } \\
\text { Infrastructure }\end{array}$ & 2.9 \\
\hline 7 & $\begin{array}{l}\text { Critique of } \\
\text { Politicians, } \\
\text { General }\end{array}$ & 2.5 & $\begin{array}{l}\text { Organization } \\
\text { of State }\end{array}$ & 2.1 & $\begin{array}{l}\text { Minimum } \\
\text { Wage }\end{array}$ & 2.5 & $\begin{array}{l}\text { International } \\
\text { Conflicts, } \\
\text { General }\end{array}$ & 2.7 \\
\hline 8 & Child Care & 2.1 & $\begin{array}{l}\text { Egyptian } \\
\text { Revolution }\end{array}$ & 1.8 & $\begin{array}{l}\text { Asylum } \\
\text { Policy }\end{array}$ & 2.1 & $\begin{array}{l}\text { Right-Wing } \\
\text { Extremism }\end{array}$ & 2.7 \\
\hline 9 & Income Divide & 2.0 & Fiscal Policy & 1.7 & $\begin{array}{l}\text { Financial } \\
\text { Crisis, } \\
\text { Greece }\end{array}$ & 1.8 & $\begin{array}{l}\text { Economic } \\
\text { Situation, } \\
\text { General }\end{array}$ & 2.0 \\
\hline 10 & Energy Policy & 1.9 & Euro & 1.7 & Euro & 1.7 & Critique of AfD & 1.9 \\
\hline
\end{tabular}

Again, these findings support the reading of Twitter as being not related to the public agenda and somewhat related to media agendas, while introducing channel-specific topic foci. Nearly $30 \%$ of hashtag mentions referred to Internet-related issues. This dominant focus is exclusive to the Twitter agenda. On rank five, we find an issue referring to the wrongful imprisonment of an individual, Gustl Mollath. This issue was originally raised in the spring of 2013, well before our period of analysis, and has been discussed in German media as one of the cases where public attention on Twitter led journalists to cover an up until then under-observed issue. During the campaign, we see the aftershocks of this issue on Twitter. At rank six, we find the issue of traffic policy and public infrastructure; these mentions are also driven by the aftershocks of two highly visible Twitter issue campaigns, the controversies about two public infrastructure projects the ill-fated Berlin airport BER and the highly controversial rebuilding of a central train station in Stuttgart, S21 [38]. Finally, we also see concerns about right-wing extremism and critique of Germany's new right-wing party Alternative für Deutschland (AfD). More in line with the media agenda is the prominence of hashtags focusing on the Egyptian revolution and the civil war in Syria.

The aspects of the Twitter agenda deviating from the public and media agendas clearly illustrate channel-specific characteristics of political talk on Twitter. We find issues highly prominent that were of specific relevance to Twitter-users (i.e., NSA scandal and government surveillance), objects of controversies with the high involvement of online activists (i.e., Gustl Mollath, traffic policy and public infrastructure), and a strong critique of right-wing extremism and populism in line with Twitter's center-left skewing user base. These findings clearly show that political talk on Twitter is much more than simply a reflection of public or media agendas.

\subsection{Temporal Dependencies Between Agendas}

In the third step of our analysis, we compare time series of issue shares on the Twitter, public, and media agendas. This might allow the identification of temporal dependencies in the salience of issues across data sets. In relying on the data available from GLES, we depend on the time span they cover. From July 8 to September 21, we have a maximum of 76 data points to compare the prominence of issues across agendas. The number of available comparisons per topic is much smaller. This is a far from an ideal basis for statistical time series analysis. We, thus, focus only on the very basic analysis of correlations between time series at time lags of $-1,0$ and +1 . Given the comparatively small number of cases, we should read results as merely illustrative.

Table 3 shows that for most topics central to political talk on Twitter, there were only weak temporal correlations to their prominence in survey responses, political coverage in newspapers, or on television. One exception is the topic "Syrian Civil War." Here, newspaper coverage and Twitter mentions correlate strongly. In most cases, though, we find only weak correlations be it for Twitter mentions of the previous day, the same day, or the following day. In our data, we, therefore, find little evidence for temporal dependencies between agendas. In interpreting these results, it is important to remember the comparatively small number of comparable observations available. Although Twitter offers a continuous time series of topical mentions, this is not the case for survey responses or media coverage. Only in the comparison between two topics on Twitter and in the survey ("NSA scandal" and "Economic 
Situation, General") do we have more than 60 comparable observations. With regard to media coverage of topics, we have even fewer observations.

The lack of comparable observations is driven by the nature of political talk online, survey responses, and political media coverage. On Twitter, talk about prominent topics is continuous. It generally starts with a massive volume spike on the day of an inciting event

Table 3. Lagged Time Series Correlations

\begin{tabular}{|c|c|c|c|c|c|c|}
\hline \multirow[b]{2}{*}{ Agendas } & \multicolumn{2}{|l|}{ Lag -1 } & \multicolumn{2}{|l|}{ Lag 0} & \multicolumn{2}{|l|}{$\mathrm{Lag}+1$} \\
\hline & $\overline{\mathbf{r}}$ & $\mathbf{n}$ & $\mathbf{r}$ & $\mathbf{n}$ & $\mathbf{r}$ & $\mathbf{n}$ \\
\hline \multicolumn{7}{|l|}{ NSA Scandal } \\
\hline Twitter - Survey & $0.33^{*}$ & 68 & $0.44^{* * *}$ & 68 & $0.34^{*}$ & 68 \\
\hline Twitter - Newspaper & $0.35^{*}$ & 57 & $0.50^{* * *}$ & 58 & $0.43^{*}$ & 58 \\
\hline Twitter - Television & 0.12 & 47 & 0.27 & 48 & 0.17 & 48 \\
\hline \multicolumn{7}{|l|}{ Government Surveillance } \\
\hline Twitter - Survey & -0.21 & 12 & 0.25 & 12 & 0.37 & 12 \\
\hline Twitter - Newspaper & 0.17 & 13 & 0.44 & 13 & 0.35 & 13 \\
\hline Twitter - Television & -- & -- & -- & -- & -- & -- \\
\hline \multicolumn{7}{|l|}{ Egyptian Revolution } \\
\hline Twitter - Survey & -- & -- & -- & -- & -- & -- \\
\hline Twitter - Newspaper & $0.47^{*}$ & 18 & $0.48^{*}$ & 19 & $0.55^{*}$ & 19 \\
\hline Twitter - Television & 0.26 & 12 & $0.60^{*}$ & 12 & 0.46 & 12 \\
\hline \multicolumn{7}{|l|}{ Syrian Civil War } \\
\hline Twitter - Survey & $0.53^{* * *}$ & 29 & 0.36 & 29 & 0.24 & 29 \\
\hline Twitter - Newspaper & $0.75^{* * * *}$ & 30 & $0.83^{* * *}$ & 31 & $0.73^{* * * *}$ & 31 \\
\hline Twitter - Television & $0.39^{*}$ & 32 & $0.56^{* *}$ & 32 & $0.43^{* *}$ & 32 \\
\hline \multicolumn{7}{|l|}{ Gustl Mollath } \\
\hline Twitter - Survey & -- & -- & -- & -- & -- & -- \\
\hline Twitter - Newspaper & -0.10 & 8 & -0.32 & 8 & -0.60 & 8 \\
\hline Twitter - Television & -- & -- & -- & -- & -- & -- \\
\hline \multicolumn{7}{|c|}{ Traffic Policy and Public Infrastructure } \\
\hline Twitter - Survey & -- & -- & -- & -- & -- & -- \\
\hline Twitter - Newspaper & 0.17 & 10 & 0.57 & 10 & 0.42 & 10 \\
\hline Twitter - Television & -0.01 & 9 & -026 & 9 & 0.47 & 9 \\
\hline \multicolumn{7}{|c|}{ International Conflicts, General } \\
\hline Twitter - Survey & 0.11 & 23 & $0.48^{*}$ & 23 & $0.54^{* *}$ & 23 \\
\hline Twitter - Newspaper & $\mathrm{n} / \mathrm{a}$ & 10 & $\mathrm{n} / \mathrm{a}$ & 10 & $\mathrm{n} / \mathrm{a}$ & 10 \\
\hline Twitter - Television & -- & -- & -- & -- & -- & -- \\
\hline \multicolumn{7}{|l|}{ Right-Wing Extremism } \\
\hline Twitter - Survey & 0.11 & 32 & -0.05 & 32 & -0.17 & 32 \\
\hline Twitter - Newspaper & $0.65^{*}$ & 13 & 0.18 & 13 & 0.47 & 13 \\
\hline Twitter - Television & -- & -- & -- & -- & -- & -- \\
\hline \multicolumn{7}{|c|}{ Economic Situation, General } \\
\hline Twitter - Survey & -0.04 & 73 & 0.05 & 73 & -0.03 & 73 \\
\hline Twitter - Newspaper & 0.11 & 12 & 0.06 & 12 & 0.14 & 12 \\
\hline Twitter - Television & -- & -- & -- & -- & -- & -- \\
\hline \multicolumn{7}{|l|}{ Critique of $A f D$} \\
\hline Twitter - Survey & -- & -- & -- & -- & -- & -- \\
\hline Twitter - Newspaper & -- & -- & -- & -- & -- & -- \\
\hline Twitter - Television & -- & -- & -- & -- & -- & -- \\
\hline
\end{tabular}

and carries on for weeks or months afterward [2]. Although there might be fluctuations in the volume of daily messages referring to a topic and even a decreasing trend, we can thus establish uninterrupted time series of daily mentions for long periods of time. The survey responses in the GLES' rolling crosssection design produce continuous time series of mentions of selected topics, given that they are mentioned regularly. In contrast, media coverage is heavily fluctuating and interrupted depending on whether a topic was covered on a given day or not. These characteristics are illustrated in Figure 3 that shows the temporal dynamics in the mention volume of the NSA scandal across the different datasets.

The different characteristics of time series shown in Figure 3 are driven by inherently different data generating processes of the data sets under analysis. Although the correlations between topical references to the NSA scandal across our data sets listed in Table 3 were only moderate, Figure 3 clearly shows that mentions follow not completely independent dynamics. Instead of interpreting these patterns as evidence of agenda setting between the different processes, we might interpret Figure 3 more appropriately as evidence of the reaction of four differing processes (i.e. public opinion, media coverage in newspapers and television, and political talk on Twitter) to an underlying cause (i.e. the NSA scandal). This is a general challenge in agenda-setting research. Do we have different agendas reacting to the same event, albeit with different coverage logics? Or, do we have a causal agenda setting process between agendas themselves? Instead of exclusively focusing on causal agenda setting processes, it might be valuable to focus on different mediating processes between agendas producing different reactions to the same underlying event $[14,36]$.

\section{Figure 3. Time Series, NSA Scandal}

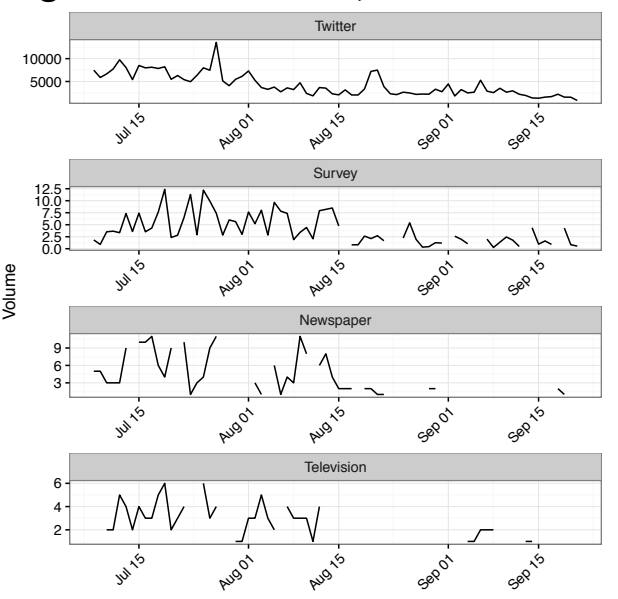

Note: Time series of the prominence of the NSA scandal on Twitter, the GLES survey, newspaper, and television coverage between July 8 and September 21

\section{Conclusion}

In this paper, we identified an issue agenda of political talk on Twitter based on popular hashtags referring to politics used in messages by politically vocal Twitter users. This Twitter agenda showed at best a weak relationship with the public agenda as measured by a public opinion survey. This indicates, that, data documenting political talk on digital services are best interpreted in the context of services' specific data generating processes and not as convenient proxy for surveys [6]. These findings indicate opportunities for more productive use of Twitter data in research. 
Instead of using it as a somewhat skewed but statistically adjustable proxy for public or media agendas, digital trace data provided by platforms like Twitter might offer insights into the shifts in the platforms' users attention to politics. Political attention is an up until now an ill-understood phenomenon. This might change given research opportunities provided by digital trace data $[2,44]$.

Naturally, this study comes with limitations. Two of which we want to address specifically. First, focusing on Germany allowed us to compare the different agendas in response to specific and shared events. Yet, this focus on a specific country raises the question if the findings reported here are generalizable to other contexts. For example, the use of Twitter in Germany is comparatively low compared to other countries, like the USA. This raises the question if a deviation of the Twitter agenda from public and media agendas, as reported by us, is actually attributable to Twitter's specific data generating process or a function of Twitter's comparatively low adoption rate. In other words, are our results driven by the Twitter agenda being qualitatively different, or by the quantity of Twitter users in Germany being low and specific and therefore less connected to the public and media agendas? This question should be addressed in further research by comparing agendas in countries with varying Twitter adoption rates.

Second, our analysis illustrated challenges for researchers inherent in the comparison between data sets of different types. While a common codebook allowed us the detailed comparison between the relative prominence of topics across data sets, our analysis remained limited by the systematically divergent characteristics of topic mentions in surveys, media coverage, and on Twitter. Consequently, some of the codes developed for traditional media channels were difficult to interpret in the context of Twitter, which led to low inter-rater-reliability scores. While we were able to provide evidence on the correspondence and divergence of agendas and topic dynamics, this forced us to stop short of establishing robust analyses of temporal influences between the agendas. Since this challenge is driven by the nature of political attitudes, political talk online, and political media coverage and not just the specifics of our case, we believe this to illustrate one of the central challenges of the systematic examination of agenda setting dynamics. Here, more qualitative case-based research designs might provide valuable complementary evidence on specific agenda-setting dynamics where quantitative research reaches its limits.

Even given these limitations, our findings are important in indicating that political talk on Twitter is distinct from public opinion on the most pressing political topics and political media coverage. Although political talk on Twitter shares topics with political media coverage, we find a communication environment characterized by the attention, interests, and motivations of politically vocal Twitter users [2, 36]. These mediating factors led political talk on Twitter to deviate in strength and dynamics from political coverage in mass media. On Twitter, therefore, we find a political communication environment interconnected with more traditional spaces of political communication but also following its own channel-specific dynamics.

\section{Acknowledgements}

This research has been supported by the Volkswagen Foundation.

\section{References}

[1] D. Lazer et al., "Computational social science," Science, vol. 323, pp. 721-723, 2009.

[2] A. Jungherr, Analyzing Political Communication with Digital Trace Data: The Role of Twitter Messages in Social Science Research. Cham: Springer, 2015.

[3] A. Jungherr, "Twitter use in election campaigns: A systematic literature review," Journal of Information Technology \& Politics, vol. 13, pp. 72-91, 2016.

[4] J. Kleinberg, "The convergence of social and technological networks," Communications of the ACM, vol. 51, pp. 66-72, 2008.

[5] J. Howison, A. Wiggins, and K. Crowston, "Validity Issues in the Use of Social Network Analysis with Digital Trace Data," Journal of the Association for Information Systems, vol. 12, pp. 767-797, 2011.

[6] A. Jungherr, "Normalizing Digital Trace Data," in Digital Discussions: How Big Data Informs Political Communication, N. J. Stroud and S. C. McGregor, Eds. New York: Routledge, 2018, pp. 9-35.

[7] S. Behrendt, A. Richter, and M. Trier, "Mixed methods analysis of enterprise social networks," Computer Networks, vol. 75, 2014.

[8] S. Domínguez and B. Hollstein, Mixed Methods Social Networks Research. Cambridge: Cambridge UP, 2014, p. 384.

[9] G. Kossinets and D. J. Watts, "Empirical analysis of an evolving social network," Science, vol. 311, pp. 88-90, 2006. [10] A. Stopczynski et al., "Measuring Large-Scale Social Networks with High Resolution," PLOS ONE, vol. 9, p. e95978, 2014.

[11] C. Wells and K. Thorson, "Combining Big Data and Survey Techniques to Model Effects of Political Content Flows in Facebook," vol. 35, pp. 33-52, 2017.

[12] C. Bail et al., "Exposure to Opposing Views can Increase Political Polarization," Proceedings of the National Academy of Sciences, 2018. 
[13] W. R. Neuman, L. Guggenheim, S. M. Jang, and S. Y. Bae, "The Dynamics of Public Attention: Agenda-Setting Theory Meets Big Data," Journal of Communication, vol. 64, pp. 193-214, 2014.

[14] A. Jungherr, "The Logic of Political Coverage on Twitter: Temporal Dynamics and Content," vol. 64, pp. 239259, 2014

[15] C. Wells et al., "How Trump Drove Coverage to the Nomination: Hybrid Media Campaigning," Political Communicationi, vol. 33, pp. 669-676, 2016.

[16] D. J. Watts, "A twenty-first century science," Nature, vol. 445, p. 489, 2007.

[17] M. E. McCombs, Setting the Agenda: Mass Media and Public Opinion, 2 ed. Cambridge: Polity, 2014.

[18] C. J. Vargo, L. Guo, M. McCombs, and D. L. Shaw, "Network Issue Agendas on Twitter During the 2012 U.S. Presidential Election," Journal of Communication, vol. 64, pp. 296-316, 2014.

[19] H. Rattinger, S. Roßteutscher, R. Schmitt-Beck, B. Weßels, and C. Wolf, "Rolling Cross-SectionWahlkampfstudie mit Nachwahl-Panelwelle (GLES 2013)," 2.0.0 ed. Köln: GESIS Data Archive, 2014.

[20] H. Rattinger, S. Roßteutscher, R. Schmitt-Beck, B. Weßels, and C. Wolf, "Campaign Media Content Analysis, Print Media (GLES 2013)," 1.0.0 ed. Köln: GESIS Data Archive, 2015.

[21] H. Rattinger, S. Roßteutscher, R. Schmitt-Beck, B. Weßels, and C. Wolf, "Wahlkampf-Medieninhaltsanalyse: Fernsehen (GLES 2013)," 1.0.0 ed. Köln: GESIS Data Archive, 2015.

[22] M. Roberts, W. Wanta, and T.-H. Dzwo, "Agenda Setting and Issue Salience Online," Communication Research, vol. 29, pp. 452-465, 2002.

[23] K. D. Sweetser, G. J. Golan, and W. Wanta, "Intermedia Agenda Setting in Television, Advertising, and Blogs During the 2004 Election," Mass Communication \& Society, vol. 11, pp. 197-216, 2008.

[24] J. K. Lee, "The Effect of the Internet on Homogeneity of the Media Agenda: A Test of the Fragmentation Thesis," Journalism and Mass Communication Quarterly, vol. 84, pp. 745-760, 2007.

[25] K. Heim, "Framing the 2008 Iowa Democratic Caucuses: Political Blogs and Second-Level Intermedia Agenda Setting," Journalism and Mass Communication Quarterly, vol. 90, pp. 500-519, 2013.

[26] S. Meraz, "Using Time Series Analysis to Measure Intermedia Agenda-Setting Influence in Traditional Media and Political Blog Networks," Journalism and Mass Communication Quarterly, vol. 88, pp. 176-194, 2011.

[27] K. Wallsten, "Agenda Setting and the Blogosphere: An Analysis of the Relationship between Mainstream Media and Political Blogs," Review of Policy Research, vol. 24, pp. 567-587, 2007.

[28] M. Scharkow and J. Vogelgesang, "Measuring the Public Agenda using Search Engine Queries," International Journal of Public Opinion Research, vol. 23, pp. 104-113, 2011.

[29] B. Sayre, L. Bode, D. Shah, D. Wilcox, and C. Shah, "Agenda Setting in a Digital Age: Tracking Attention to California Proposition 8 in Social Media, Online News and
Conventional News," Policy \& Internet, vol. 2, pp. 7-32, 2010.

[30] F. Diaz, M. Gamon, J. M. Hofman, E. Kiciman, and D. Rothschild, "Online and Social Media Data As an Imperfect Continuous Panel Survey," PLoS One, vol. 11, p. e0145406, 2016.

[31] M. A. Bekafigo and A. McBride, "Who tweets about politics? Political participation of Twitter users during the 2011 gubernatorial elections," Social Science Computer Review, vol. 31, pp. 625-643, 2013.

[32] E. Hargittai, "Is Bigger Always Better? Potential Biases of Big Data Derived from Social Network Sites," The ANNALS of the American Academy of Political and Social Science, vol. 659, pp. 63-76, 2015.

[33] Y.-R. Lin, B. Keegan, D. Margolin, and D. Lazer, "Rising tides or rising stars? Dynamics of shared attention on Twitter during media events," PLoS One, vol. 9, p. e94093, 2014.

[34] L. Guggenheim, S. M. Jang, S. Y. Bae, and W. R. Neuman, "The Dynamics of Issue Frame Competition in Traditional and Social Media," The Annals of the American Academy of Political and Social Science, vol. 659, pp. 207224, 2015.

[35] D. Trilling, "Two Different Debates? Investigating the Relationship Between a Political Debate on TV and Simultaneous Comments on Twitter," Social Science Computer Review, vol. 33, pp. 259-276, 2015.

[36] A. Jungherr, H. Schoen, and P. Jürgens, "The Mediation of Politics Through Twitter: An Analysis of Messages Posted During the Campaign for the German Federal Election 2013," Journal of Computer-Mediated Communication, vol. 21, pp. 50-68, 2016.

[37] W. L. Bennett and A. Segerberg, The Logic of Connective Action: Digital Media and the Personalization of Contentious Politics. Cambridge: Cambridge UP, 2013.

[38] A. Jungherr and P. Jürgens, "Through a glass, darkly: Tactical support and symbolic association in Twitter messages commenting on Stuttgart 21," Social Science Computer Review, vol. 32, pp. 74-89, 2014.

[39] B. A. Conway, K. Kenski, and D. Wang, "The Rise of Twitter in the Political Campaign: Searching for Intermedia Agenda-Setting Effects in the Presidential Primary," Journal of Computer-Mediated Communication, vol. 20, pp. 363380, 2015.

[40] R. Schroeder, Social Theory after the Internet Media, Technology, and Globalization. UCL P, 2018.

[41] B. Frees and B. van Eimeren, "Ergebnisse der ARD/ZDF-Onlinestudie 2013," Media Perspektiven, vol. 8, pp. 373-408, 2013.

[42] W. Koch and B. Frees, "Dynamische Entwicklung bei mobiler Internetnutzung sowie Audios und Videos. Ergebnisse der ARD/ZDF-Langzeitstudie.," Media Perspektiven, vol. 9, pp. 418-437, 2016.

[43] A. Jungherr, "Four Functions of Digital Tools in Election Campaigns: The German Case," The International Journal of Press/Politics, vol. 21, pp. 358-377, 2016.

[44] A. Jungherr, H. Schoen, O. Posegga, and P. Jürgens, "Digital Trace Data in the Study of Public Opinion: An Indicator of Attention Toward Politics Rather Than Political Support," Social Science Computer Review, vol. 35, pp. 336356, 2017. 